\title{
Reabilitação Ambiental: a Vegetação Além do Paisagismo
}

\author{
CORRÊA, Rodrigo Studart \\ Universidade de Brasília, Brasília - DF, Brasil. Email: rscorrea@unb.br
}

\section{Resumo}

A presença de vegetação em cidades tem sido majoritariamente entendida como paisagismo. Todavia, além do paisagismo, plantas exercem mais de vinte serviços ambientais no meio urbano e melhoram a qualidade de vida nas cidades. Amenização da temperatura, manutenção da boa qualidade do ar, regulação hídrica, facilitação da mobilidade urbana e lazer são alguns dos serviços prestados a populações humanas pela vegetação presente nas cidades. A degradação urbana possui várias causas, mas a reabilitação de espaços urbanos degradados conta invariavelmente com o uso de plantas. Exemplos de uso e da importância da vegetação como elemento acessório ou principal de reabilitação ambiental urbana são apresentados neste artigo. $O$ conceito contemporâneo de cidade preconiza que espaços urbanos devam apresentar áreas verdes e corredores ecológicos permeando a malha edificada. Os serviços prestados pela vegetação urbana às populações das cidades são imensos e monetariamente imensuráveis pela sua grandeza. Todavia, esses serviços são somente percebidos quando ausentes.

Palavras-Chave: Revegetação, reabilitação, requalificação, restauração, serviços ambientais, paisagismo.

\begin{abstract}
The presence of vegetation in cities has usually been understood as landscaping. However, besides landscaping plants provide more than twenty environmental services in urban areas and improve life quality. Temperature softening, maintenance of a good air quality, water regulation, urban mobility facilitation and leisure are some of the services provided by vegetation established in cities to humans. Urban degradation has several causes, but the rehabilitation of degraded urban areas invariably relies on the use of plants. Examples of vegetation use and its importance as accessory or chief element for environmental rehabilitation in cities are presented in this paper. Contemporary concept of city prescribes that green areas and ecological corridors shall flow across urban areas along built spaces. The services provided by urban vegetation to city inhabitants are immense and monetarily immeasurable due to its greatness. However, these services are only perceived when they are absent.
\end{abstract}

Key-Words: Revegetation, rehabilitation, requalification, restoration, environmental services, landscaping. 


\section{Introdução}

Árvores são monumentos naturais (FISCHESSER, 1981) e, como tais, os primeiros jardins criados pelo homem na China e no Egito tentavam reproduzir o paraíso na Terra (LIMA e MACHADO, 2003). O paisagismo contemplativo utiliza a vegetação sob o critério visual e é a atividade mais comum de cultivo de plantas em áreas urbanas. No Ocidente, os laços entre arquitetura e paisagismo surgiram com a visão de que plantas na paisagem urbana representavam uma intervenção tardia na arquitetura mal-acabada (LIMA e MACHADO, 2003).

Ainda assim, a primeira manifestação paisagística no Brasil remonta ao século XVII, quando Maurício de Nassau arborizou parte de Pernambuco com espécies cítricas exóticas à flora brasileira (LIMA e MACHADO, 2003). Mas, no Rio de Janeiro do século XIX, árvores no meio urbano não eram bemvistas, porque a população carioca temia que elas atraíssem animais indesejáveis.

A vegetação implantada em áreas urbanas ainda é majoritariamente percebida como paisagismo contemplativo, que busca harmonizar ambientes e prover conforto visual a observadores. Todavia, a vegetação no meio urbano exerce funções ambientais além do paisagismo, mas que passam despercebidas pela maioria das pessoas. A demografia exerce influência sobre a satisfação humana (MORRIS e GUERRA, 2014), e espaços vegetados auxiliam na distribuição (1) e na densidade de bairros (2) e do tráfego (3), criam local para recreação (4), cultura (5) e esporte (6), valorizam imóveis (7), evitam invasão humana (8), exercem influência na regulação climática (9), no conforte acústico (10) e na circulação de ventos (11), sequestram carbono (12), reduzem a poluição do ar (13), amortecem eventos naturais extremos (14), atenuam os efeitos dos períodos de estiagem (15), amortecem enxurradas (16), reduzem a erosão do solo (17), auxiliam a recarga de aquíferos (18), abrigam a fauna que controla a proliferação de pragas urbanas (19), contribuem para a manutenção da biodiversidade (20), servem como objeto de educação ambiental (21), entre outros.

Além da função estética, a concepção funcional do paisagismo urbano procura tirar o máximo proveito dos serviços que árvores isoladas ou agrupadas em bosques, florestas, parques e outros ambientes possam oferecer. Áreas urbanizadas funcionam como ilhas de calor, onde as temperaturas são mais altas e a umidade relativa do ar mais baixa do que em zonas rurais e naturais. Nas metrópoles brasileiras, ocorrem diferenças de até $100 \mathrm{C}$ entre bairros arborizados e não arborizados nas horas mais quentes do dia no verão (BAPTISTA, 2003). Não é mera coincidência que bairros mais quentes são justamente aqueles com menor percentagem de cobertura vegetal. Em nível regional, a absorção de água e a transpiração das plantas são fundamentais para manter o ciclo hidrológico e, conseqüentemente, as condições climáticas regionais (PRIMACK e RODRIGUES, 2002).

Sombra e evapotranspiração transformam árvores em amenizadores da temperatura e umidificadores do ar. Alguns cálculos comparam uma árvore adulta ao poder de resfriamento de cinco aparelhos de ar condicionado (PRIMACK e RODRIGUES, 2002). Espaços vegetados são atualmente concebidos como parte da infraestrutura urbana. O verde urbano, formado por parques, praças, rotatórias, ruas arborizadas, jardins, remanescentes de vegetação nativa e outros, é capaz de transformar paisagens, amenizar o clima árido das cidades e melhorar a qualidade de vida de suas populações (SANCHES, 2011).

Os critérios de escolha de plantas a serem usadas em áreas urbanas não devem limitar-se à função estética e à regulação do microclima. Mitigação de impactos ambientais, corredores ecológicos e afirmação do bioma natural, por meio do uso de espécies nativas, são alguns critérios contemporâneos usados na construção e reabilitação de espaços urbanos (LIMA e MACHADO, 2003; SANCHES, 2011).

Belo Horizonte nasceu e cresceu como Cidade Jardim, mas foi em Brasília que o verde tomou dimensões colossais. Buscou-se com a Nova Capital o sonho de uma cidade em meio a um bosque, onde a natureza fizesse parte do cotidiano de seus habitantes (ALENCAR et al. 2008). Os amplos espaços vegetados, denominados de escala bucólica no plano diretor da cidade, foram concebidos como forma de organizar e distribuir setores e edificações pertencentes às escalas monumental (palácios e prédios públicos), gregária (prédios comerciais) e residencial. A vegetação urbana é, portanto, vital para a estruturação de Brasília e representa um dos quatro pilares do planejamento urbano da Nova Capital. A escala bucólica integra sem percepção de transição as 
demais escalas concebidas durante a criação da cidade (CARDOSO et al., 2010). A escala bucólica permeia e se estende pela cidade em corredores verdes que, sob o conceito atual de ecologia da paisagem, formam corredores ecológicos (Figura 1).

A arborização urbana de Brasília priorizou, em sua fase inicial de implantação (1960 - 1970), espécies classicamente utilizadas no paisagismo urbano de diversas cidades brasileiras, tais como cambui (Peltophorum dubium Taub), flamboyant (Delonix regia Raf), sibipiruna (Caesalpinea peltophoroides Ducke) e outras. Essas espécies desempenhavam funções ambientais no meio urbano, mas eram ecologicamente questionáveis para o bioma local. Seguiu-se com o plantio de espécies frutíferas, como mangueiras (Mangifera indica L.) e jaqueiras (Artocarpus integrifolia L. f.). Finalmente, a opção por espécies nativas tornou-se rotina a partir da década de 1980 (CARDOSO et al., 2010). A adoção de espécies nativas reflete o início da valorização do Cerrado pelos brasilienses e a preocupação de se acoplarem funções ecológicas às funções ambientais da vegetação que compõe a escala bucólica de Brasília.

Em 2010 Brasília contava com cerca de 250 espécies de árvores compondo sua escala bucólica, das quais 108 eram atrativas de fauna e 88 eram nativas do Cerrado brasileiro, bioma original do sítio em que a cidade se situa (ALENCAR et al. 2008; CARDOSO et al., 2010). Parte das funções ecológicas dessas espécies arbóreas pode ser retratada pela presença de 144 espécies de aves na área urbana da cidade, que correspondem a mais de $1 / 3$ do número de espécies de aves que habitam o Distrito Federal. Aves são utilizadas como bioindicadores de qualidade ambiental, e a elevada diversidade da avifauna coincide com a qualidade ambiental proporcionada pelo verde da cidade. Apesar da tipologia urbana que habitam, essas aves são majoritariamente nativas do Cerrado, mais de $40 \%$ das espécies são insetívoras (CADAVAL, 1996) e, portanto, prestam inestimável serviço no controle de vetores de doenças humanas.

Outro fato notável na cidade é o papel desempenhado pelos jardins residenciais particulares. $\mathrm{O}$ alinhamento desses jardins criou coletivamente corredores de fauna, sem que houvesse um planejamento mais abrangente para isso acontecer (CADAVAL, 1996; LIMA e MACHADO, 2003). A elevada proporção de espaços vegetados que permeiam a malha urbana de Brasília, distribuídos entre áreas públicas e privadas, elevam a qualidade ambiental da cidade e de vida de seus moradores (Figura 1). As funções ambientais associadas à escala bucólica da cidade seriam monetariamente impagáveis, caso desempenhadas por meios diversos da vegetação.

Figura 1: Escalas residencial, gregária e bucólica de Brasília.

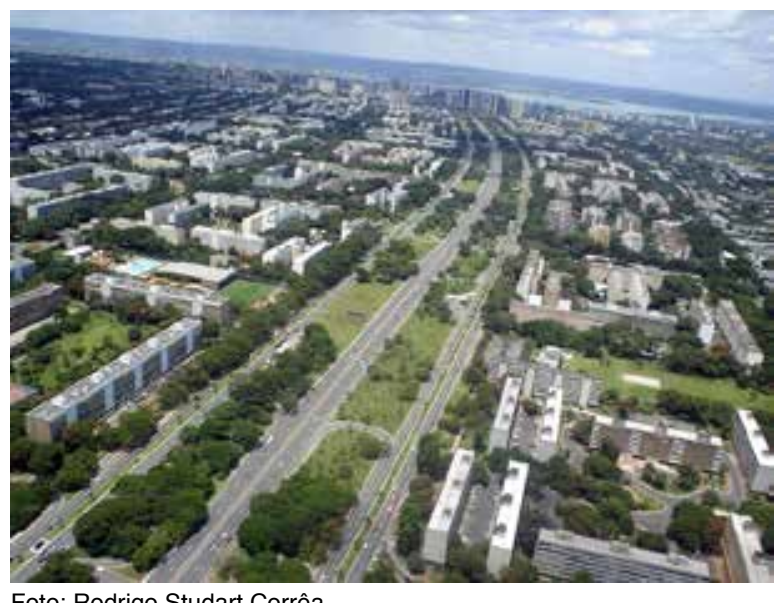

Foto: Rodrigo Studart Corrêa.

\section{Degradação}

Espaços degradados referem-se a áreas desmatadas, ecossistemas destruídos e solos erodidos ou estéreis. No meio urbano, espaços degradados referem-se a locais abandonados, áreas desprovidas de funções sociais, ambientais ou econômicas ou, ainda, a áreas utilizadas à revelia de suas vocações (CORRÊA, 2009).

Espaços degradados no meio urbano geralmente surgem pelo abandono de empreendimentos, pressão por moradia, especulação imobiliária, expansão descontrolada, excesso de verticalização, adensamento predial e populacional, deterioração arquitetônica, baixa proporção de área verde per capita, congestionamentos, falta de saneamento, poluição e outros (SANCHES, 2011; SCARINGELLA, 2001). O adensamento urbano, por exemplo, provoca a redução de espaços livres, aumenta a impermeabilização da superfície do solo, limita a circulação de ventos e deteriora a qualidade ambiental nas cidades.

Há ainda fatores imateriais que são considerados causas e sinais de degradação urbana, tais como desemprego, criminalidade, sistemas públicos ineficientes ou inoperantes e falta de opções de lazer (SCARINGELLA, 2001). 
Outra fonte significativa de degradação nas cidades surge do encontro da malha urbana, como resultado de sua expansão, com jazidas de mineração (Figura 2), lixões, aterros e outras atividades que originalmente se encontravam em zonas rurais (SANCHES, 2011). Além disso, o processo de urbanização é per se degradador do meio natural e causa a ele impactos de toda sorte.

A extração de bens minerais para a urbanização e construção civil gera profundos impactos ambientais, representados pelas cavas de mineração e pelas pilhas de material estéril, que são de pouca serventia e difícil recuperação (CORRÊA, 2009). Nas sociedades desenvolvidas, cada indivíduo consome por ano cerca de nove toneladas de bens minerais usados na construção civil (CADAVAL, 1996).

Da mesma forma, seres urbanos consomem mais água (150 litros/habitante/dia) e bens que seres rurais (60 litros/habitante/dia) e, portanto, geram maiores volumes de esgoto e resíduos. Reformas são particularmente degradadoras, porque estimulam a mineração de materiais e geram resíduos da construção civil. Cidades geram mais impactos, resíduos e fontes de degradação do que podem absorver. A solução tem sido exportar esses passivos ambientais para áreas rurais ou periurbanas. Porém, quando isso não é possível, deve-se reabilitar o objeto degradado no próprio espaço urbano.

Figura 2: Área minerada na periferia de Sydney, Austrália, cuja reabilitação resultou na implantação da vila olímpica dos Jogos Olímpicos de 2000.

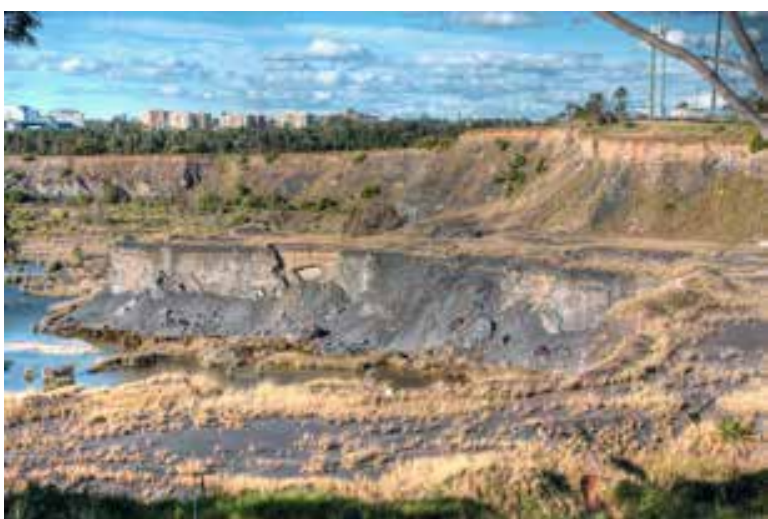

Foto: Adam. J. W. C, em http://commons.wikimedia.org/wiki/ File:Former_quarry_at_olympic_park_sydney.jpg\#mediaviewer/ File:Former_quarry_at_olympic_park_sydney.jpg. Acesso em $5 / 3 / 2015$

\section{Reabilitação}

Reabilitar é prover forma e função para espaços considerados degradados. Restaurar ecossistemas, remediar áreas contaminadas, reconfigurar paisagens, recuperar solos erodidos, revegetar superfícies expostas e requalificar espaços abandonados são algumas feições da reabilitação ambiental (CORRÊA, 2009). Nesse sentido, a requalificação de espaços urbanos degradados geralmente demanda o uso de vegetação como elemento acessório ou principal. A introdução de vegetação nesses espaços é capaz de resgatar parte da qualidade ambiental perdida nas cidades (SANCHES, 2011).

Um dos primeiros e maiores projetos de reabilitação ambiental no Brasil refere-se à Floresta da Tijuca, fruto da transformação de lavouras de café em áreas destinadas à produção de água. A população carioca sofria desde 1824 com a falta d'água potável e a situação se tornou crítica em 1860. D. Pedro II desapropriou lavouras de café situadas em áreas de recarga e em 1861 decretou a criação nesse espaço da Floresta da Tijuca.

Logo após a criação legal da Floresta da Tijuca, D. Pedro II determinou o reflorestamento da área. A recomposição florestal da Tijuca foi um dos primeiros trabalhos de reabilitação por meio do reflorestamento em todo mundo, seguramente o primeiro da América do Sul. Um ano após o início dos trabalhos, quase 14 mil árvores de 23 espécies haviam sido plantadas. Até 1874, o primeiro administrador da Floresta da Tijuca, Maj. Acher, e sua equipe haviam plantado quase 62 mil árvores. Administradores se sucederam, plantaram outras 30 mil árvores e realizaram trabalhos de paisagismo, transformando a floresta em parque de uso público. Atualmente, a Floresta da Tijuca oferece serviços ambientais de toda sorte, inclusive um cenário privilegiado, no qual cidade, natureza e cultura se harmonizam e se complementam. A maior floresta replantada do mundo em área urbana emoldura a cidade e se tornou indissociável da paisagem carioca.

O maciço florestal da Tijuca provê inimagináveis serviços ambientais à população carioca. Essa floresta amortece, armazena, filtra e distribui águas pluviais, neutraliza a acidez das chuvas formadas em áreas poluídas, aumenta a estabilidade das encostas, sequestra carbono de origem antrópica, 
intercepta anualmente 3,5 toneladas de cobre, chumbo e zinco, que contaminariam a área urbana, reduz a densidade demográfica e evita conurbações (COELHO NETTO, 2005). Além dos serviços invisíveis à população, a Floresta da Tijuca provê lazer aos cariocas, turismo para os visitantes e cria identidade internacionalmente conhecida para a cidade do Rio de Janeiro.

Nos Estados Unidos, estudo sobre a influência do verde urbano em dez cidades norte-americanas revelou que uma vida humana é salva a cada ano em cada cidade por causa da interceptação e absorção de poluentes pelas árvores. Em Nova lorque, as áreas verdes salvam oito vidas por ano ao removeram quase duas mil toneladas de poluentes do ar (NOWAK et al., 2014). Além disso, a agricultura urbana tem ocupado espaços ociosos na cidade, aumentado a proporção de cobertura verde e incorporando funções rurais a essa metrópole.

No Distrito Federal, árvores foram recomendadas em área urbana por razões sanitárias. Algumas cidades do Distrito Federal - DF experimentaram urbanização acelerada, predatória e descontrolada a partir da década de 1990. Na cidade de São Sebastião - DF, por exemplo, a ocupação humana ocorreu à custa de um rápido desmatamento para implantação de bairros e estruturas urbanas. A retirada indiscriminada da cobertura vegetal e a condição úmida de baixada da área onde foram assentadas cerca de vinte mil famílias permitiram a proliferação de insetos e roedores que transmitem dengue, malária, leishmaniose, febre amarela e hantavirose. Em outras áreas, especialistas também atribuíram o surgimento de casos de febre amarela ao desmatamento de vegetação de Cerrado (OLIVEIRA, 2008).

Além do controle convencional de vetores, o plantio de árvores em São Sebastião, para reintrodução de aves predadoras de insetos e roedores, foi indicado como medida sanitária para o caso. Árvores abrigam diversas formas de vida e de relações ecológicas (Figura 3) e, portanto, são capazes de transformar paisagens e reequilibrarem ecossistemas (OLIVEIRA, 2008). Levantamentos posteriores identificaram que 146 hectares da malha urbana de São Sebastião poderiam ser arborizados com espécies nativas, provendo 14,6 m2 de área verde por habitante (OLIVEIRA, 2008), valor superior ao recomendado pela Organização Mundial de Saúde - OMS (12 m2/habitante).
Figura 3: Árvore como abrigo de ave predadora de vetores de doenças.

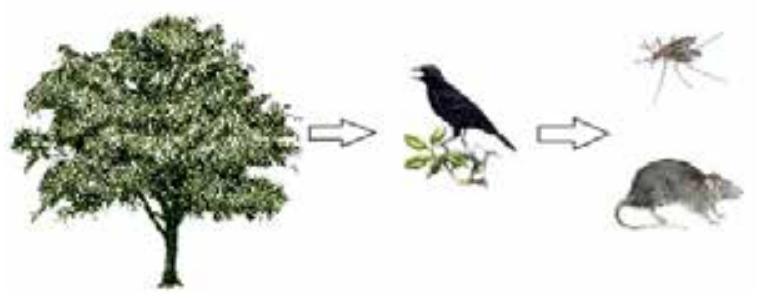

Fontes: www.candela.blogger.com.br, www.labcon.com.br, ww2. prefeitura.sp.gov.br, www1.istockphoto.com apud Oliveira (2008).

A revegetação como meio de reabilitação também pode ser materializada em corredores verdes ao longo das linhas naturais de drenagem nas cidades. O Código Florestal brasileiro define que Áreas de Preservação Permanente - APPs (Lei no 12.651/2012) são espaços que devem permanecer desocupados e sob cobertura vegetal, inclusive em áreas urbanas. Faixas vegetadas nas APPs atenuam inundações e funcionam como filtros naturais das águas pluviais que alcançam cursos e corpos d'água. Em outros locais, APPs auxiliam a estabilização de terrenos, evitam desmoronamentos e quedas de barreiras. Apesar da importância e serviços que APPs prestam, o desmatamento e a ocupação delas nas cidades brasileiras é a regra vigente.

Cidades geralmente surgem à margem de cursos d'água, e o tratamento urbano do espaço desconsidera a necessidade de se manter uma faixa vegetada ao longo dos rios para se proteger o recurso hídrico. Poluição e contaminação da água, assoreamento e enchentes são frequentes no cenário urbano brasileiro. Por esses motivos, a restauração de ecossistemas em APPs no meio urbano deve ser priorizada (SANCHES, 2011), mas poucas cidades têm investido na reabilitação desses espaços.

A reabilitação de APPs ao longo das linhas de drenagem no meio urbano resulta na formação de corredores verdes, onde pedestres e ciclistas podem se locomover sob a sombra da cobertura vegetal. Algumas experiências de criação de corredores verdes mostraram que essas áreas incentivam a mobilidade de pedestres e ciclistas (SANCHES, 2011) e, portanto, aliviam congestionamentos. Além disso, pessoas que adotam a bicicleta como meio de locomoção urbana são mais felizes que usuários de veículos automotores nas cidades (MORRIS e GUERRA, 2014). São Paulo, que é uma cidade 
de difícil tráfego de veículos, abriga o quarto maior parque linear do mundo, com $30 \mathrm{~m}$ de largura e 7,5 km de extensão: Parque da Integração Zilda Arns (SANCHES, 2011). Portanto, corredores verdes devem ser criados como espaços de proteção de recursos hídricos e otimizados como rotas de mobilidade nas cidades.

No Brasil há inúmeros projetos de restauração de APPs na zona rural, mas poucos exemplos no espaço urbano. O Parque Gleba E, no Rio de Janeiro, é um bom exemplo de reabilitação urbana por meio da restauração de ecossistemas de mangue e restinga, definidos como APPs pelo Código Florestal Brasileiro - Lei no 12.651/2012 (SANCHES, 2011). Em uma área de 66 hectares às margens de um complexo lagunar na Barra da Tijuca, a cidade do Rio de Janeiro conciliou nesse parque lazer humano e proteção a ecossistemas naturais.

Em várias partes do mundo, parques têm sido criados como forma de reabilitar áreas de lixões e aterros sanitários desativados. A primeira iniciativa desse tipo remonta 1926, em Seattle - EUA. No Brasil, o Parque Raposo Tavares, criado em 1981 em São Paulo, representa a primeira iniciativa desse tipo na América Latina (SANCHES, 2011). No Distrito Federal, uma área de 60 hectares, que abrigou por meio século o lixão da Capital Federal, será revegetada e transformada em área verde. O local de deposição do lixo situase à margem do Parque Nacional de Brasília, Unidade de Conservação de Proteção Integral (Lei no 9985/200), e da Cidade Estrutural, uma área residencial, carente de lazer e densamente povoada por mais de 35 mil habitantes. Pretende-se reabilitar o espaço por meio da arborização com espécies preferencialmente nativas do Cerrado brasileiro. Essa concepção de revegetação busca conciliar as necessidades ecológicas do Parque Nacional de Brasília às necessidades de lazer da população que habita sua margem.

A maioria das cidades brasileiras apresenta jazidas mineradas à margem da malha urbana ou mesmo dentro dela (SANCHES, 2011). A recuperação de áreas mineradas representa o caso extremo de degradação e, consequentemente, de reabilitação (CORRÊA, 2009). Projetos de revegetação de áreas mineradas geralmente visam restabelecer funções ao local, sobretudo ecológicas (CORRÊA, 2009). topográficos, edáficos e biológicos. Portanto, a reabilitação de jazidas representa uma oportunidade única de se agregar todo tipo de forma e função a um local reconstruído a partir de escombros. A distribuição de bosques de espécies nativas ao longo de um passeio é uma opção (Figura 4) que agrega lazer, esporte, paisagismo, funções ecológicas das espécies nativas, educação ambiental (pela aproximação entre frequentadores e flora nativa), entre outras funções ambientais.

Porém, há inúmeros projetos de reabilitação de áreas mineradas em que o paisagismo tornarse um forte componente. A criação de parques comunitários nessas áreas é um desses casos (Figura 5).

Em face da intensidade de dano que a mineração provoca, a reabilitação de jazidas requer grande imaginação, boa técnica e vultosos recursos financeiros. Curitiba enfrentou com muita criatividade a degradação surgida pelo encontro da malha urbana com pedreiras abandonadas. A reabilitação dessas pedreiras por meio da requalificação do uso do espaço resultou na criação de parques, casas de espetáculos, espaços para apresentações e outros usos públicos (Figura 5). Em outras cidades brasileiras, como São Paulo, algumas áreas verdes e parques também nasceram da reabilitação de áreas mineradas, tais como o Parque Ibirapuera, a Raia Olímpica da Universidade de São Paulo e o Parque Ecológico Tietê (SANCHES, 2011).

Figura 4: Ópera de Arame, edificada como forma de reabilitar pedreira em Curitiba, Paraná.

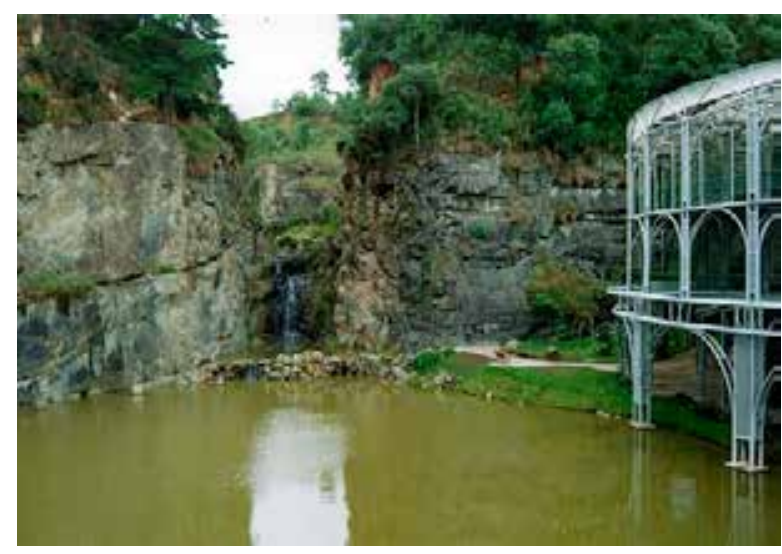

Foto: Rodrigo Studart Corrêa. 
Figura 5: Projeto de parque comunitário como meio de reabilitar área minerada em Brasília, Distrito Federal.

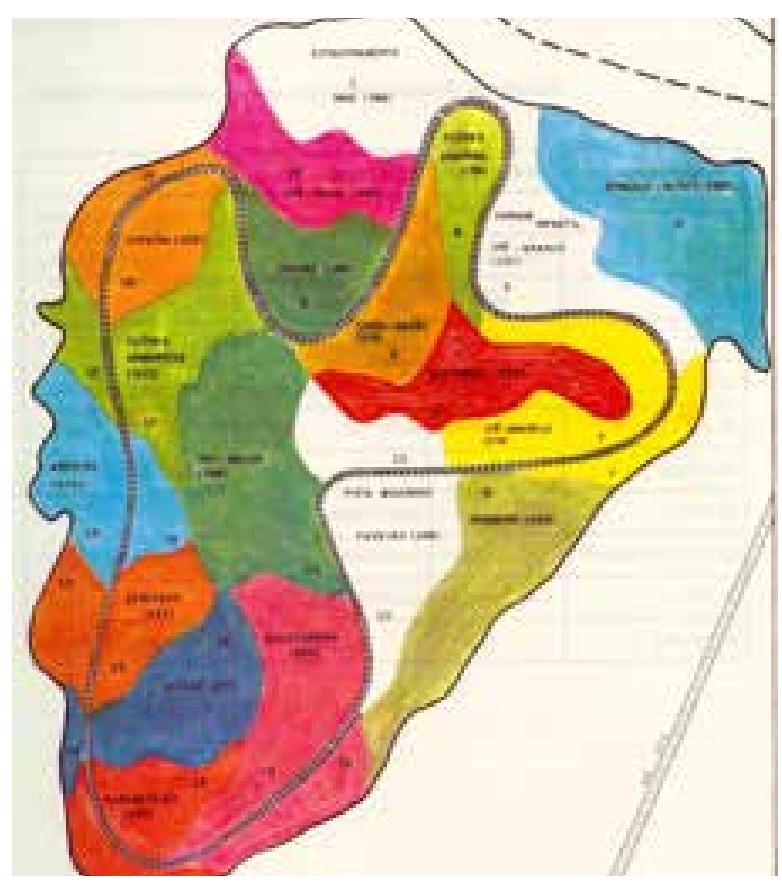

Fonte: Rodrigo Studart Corrêa.

Na Austrália, áreas mineradas e contaminadas em Homebush Bay (Figura 2) foram integradas à malha urbana de Sydney, quando foi necessário adquirir espaço para se construir a vila dos Jogos Olímpicos de 2000. A reabilitação da área se iniciou com trabalhos de remediação e reconfiguração topográfica, que foram sucedidos por trabalhos de urbanismo, paisagismo e arborização. Houve a criação de malha urbana e viária, parques e outros aspectos que elevaram a qualidade ambiental do local e o tornaram habitável. O projeto de reabilitação transformou uma grande extensão degradada, sem uso e com baixo valor monetário, em área urbana ambientalmente saudável e monetariamente valorizada. A vegetação, como sempre, foi elemento essencial na reabilitação de Homebush Bay (Figura $6)$.

Figura 6: Bicentennial Park, implantado como parte da reabilitação de Homebush Bay, Austrália.

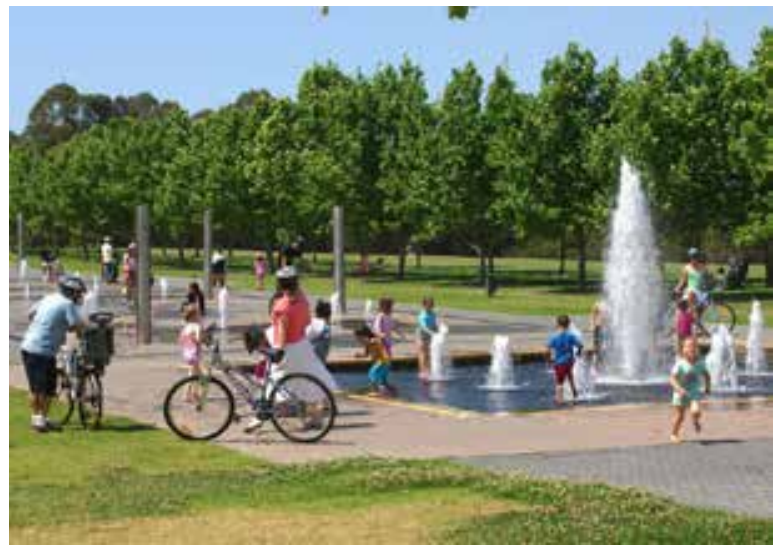

Fonte:hhttp://sydneyforeveryone.com.au/city/homebush/west-andsouthwest-walks/bicentennial-park-homebush-bay/. Acesso em 21/4/2015.

A reabilitação ambiental não resgata apenas espaços físicos, mas também transforma o meio social. Áreas degradadas são facilmente ocupadas por atividades ilícitas que excluem a população do local. A requalificação desses espaços em áreas de uso comunitário torna-os atrativos e mais seguros. Essas características fomentam a convivência social, a criação de identidade local e, em muitos casos, a geração de renda e empregos (SANCHES, 2011).

As grandes cidades brasileiras apresentam limitadas opções de aquisição de novos espaços livres, e a transformação de espaços urbanos degradados em espaços vegetados resolve o problema representado pela degradação e atenua a pressão urbana em áreas adensadas (SANCHES, 2011). A requalificação de espaços urbanos degradados reduz também a pressão por aquisição de novos espaços em áreas rurais.

A ecologia da paisagem divide uma cidade em matriz urbana, manchas verdes e corredores ecológicos. A matriz é representada pela paisagem eminentemente urbana. As manchas são representadas no ambiente urbano por parques $e$ outras áreas vegetadas. Os corredores ecológicos são linhas de vegetação ao longo de avenidas, da drenagem natural, parques lineares e outros, que interligam as manchas verdes e dão sustentabilidade ecológica às cidades (SANCHES, 2011). A cidade contemporânea deve permitir que manchas verdes e corredores ecológicos se misturem à matriz urbana. Os serviços ambientais prestados pela vegetação no meio urbano são imensos, mas somente percebidos quando ausentes. 


\section{Conclusão}

A introdução de vegetação nas cidades iniciouse como pratica paisagística. Atualmente, plantas são invariavelmente demandadas em projetos de reabilitação, porque exercem mais de vinte funções ambientais no meio urbano e melhoram a qualidade de vida de populações humanas. Sob o conceito contemporâneo de urbanismo, a vegetação tornouse elemento indissociável das cidades e inúmeros são os exemplos do uso de plantas em projetos de reabilitação de espaços urbanos no Brasil e em outros países.

A tecnologia humana ainda não criou um substituto à altura de uma planta, que aglomera beleza e funções ambientais em um único indivíduo. Portanto, devemos aprender a maximizar os benefícios cênicos e funcionais desse ser que a natureza criou.

\section{Agradecimentos}

O autor agradece à Comissão Editorial, pela escolha do tema desta edição especial, e aos Revisores no manuscrito, cujos comentários e correções melhoraram este trabalho.

\section{Referências}

ALENCAR, F. O. C. C.; MARTINS, J. L.; RODRIGUES, M. G. R.; CORDEIRO, R. G.; LIMA FILHO, R.M.; ULHÔA, S. C. LIMA, S. C. Arborização urbana no Distrito Federal - história e espécies do Cerrado. Brasília: Novacap, 2008.

BAPTISTA, G. M. M. Ilhas urbanas de calor. Scientific American Brasil, v. 8, n. 8, p. 54-59, 2003. CADAVAL, L. Mapeamento de biótopos no Distrito Federal - Projeto Piloto de Brasília. Brasília: FABrandt/MMA/IEMA, 1996.

CARDOSO, E. S.; GUIMARÃES. G. S; CORRÊA, R. S. MOTA, E. D. F.; NETTO, P. B. Levantamento florístico da arborização urbana no Distrito Federal: espécies, o estado de conservação e a formação de corredor ecológico. In: Anais. XIV Congresso Brasileiro de Arborização Urbana. Sociedade Brasileira de Arborização Urbana e International Society of Arboriculture. Bento Gonçalves - RS, 28/11 a 3/12 de 2010.

COELHO NETTO, A. L. A interface florestal-urbana e os desastres naturais relacionados à água no maciço da Tijuca: desafios ao planejamento urbano numa perspectiva sócio-ambiental. Revista do Departamento de Geografia, v. 16, n. 1, p. 46-60, 2005.

CORRÊA, R. S. Recuperação de áreas degradadas pela mineração no Cerrado: manual para revegetação. Brasília: Universa, 2009.

FISCHESSER, D. Conhecer as árvores. Coleção Euroagro. São Joaquim - RS: Publicações EuropaAmérica, 1981.

MORRIS, E. A; GUERRA, E. Mood and mode: does how we travel affect how we feel? Transportation, v. 42 , n. 1, p. 25-43, 2014.

NOWAK, D. J.; HIRABAYASHI, S.; BODINE, A.; GREENFIELD, E. Tree and forest effects on air quality and human health in the United States. Environmental Pollution, v. 193, p. 119-129, 2014.

OLIVEIRA, V. Z. Reabilitação sanitária e paisagística de Sebastião - DF por meio de arborização urbana. 2008. Monografia (Especialização). Reabilita - PósGraduação lato sensu em Reabilitação Ambiental Sustentável Arquitetônica e Urbanística. Faculdade de Arquitetura e Urbanística - Universidade de Brasília, Brasília, 2008.

PRIMACK, R. B.; RODRIGUES, E. Biologia da conservação. Londrina: Primack, R. B.; Rodrigues, E., 2002.

LIMA, S. C.; MACHADO, E. A história dos jardins. In: Manual de jardinagem e produção de mudas do Departamento de Parques e Jardins - DPJ. Companhia Urbanizadora da Nova Capital NOVACAP. Brasília, p.7-22, 2003.

SANCHES, P. M. De áreas degradadas a espaços vegetados: potencialidades de áreas vazias, abandonadas e subutilizadas como parte da infra-estrutura verde urbana. 2011. Dissertação (Mestrado) - Faculdade de Arquitetura e Urbanismo, Universidade de São Paulo, São Paulo, 2011.

SCARINGELLA, R. S. A crise da mobilidade urbana em São Paulo. São Paulo em Perspectiva, v. 15 n.1, p. 55-59, 2001. 